\title{
Hypertension following cadaveric renal transplantation
}

\author{
G. A. Coles \\ M.D., M.R.C.P. \\ G. R. JONES \\ M.R.C.P.(Ed.)
}

\author{
D. L. Crosby \\ F.R.C.S. \\ J. H. JONES \\ M.D., M.R.C.P.
}

Cardiff Royal Infirmary

\author{
S. MCVEIGH
}

\section{M.R.C. Blood Pressure Research Unit, Glasgow}

\section{Summary}

The incidence and aetiology of hypertension following cadaveric-donor renal transplantation have been investigated in twenty-four patients. Initially, the diastolic blood pressure was persistently above 100 $\mathrm{mmHg}$ in $52 \%$ of the patients. By 1 month after renal transplantation the incidence had fallen to $17 \%$ but it then increased rapidly, so that by 5 months $83 \%$ had hypertension.

Changes in blood pressure correlated poorly with changes in the dose of prednisone, extracellular fluid volume, exchangeable sodium, creatinine clearance and haemoglobin.

The recipient's original diseased kidneys were removed after transplantation in seven patients. The blood pressure fell to normal levels in three, remained unchanged in two and became easier to control with antihypertensive drugs in the other two patients. Measurements of plasma renin concentration were of no value in predicting the response to recipient nephrectomy.

\section{Introduction}

After renal transplantation most patients who previously had high blood pressure rapidly become normotensive (Ducrot et al., 1965). For various reasons the hypertension may, however, recur (Hume, 1967). We have been impressed by the high proportion of transplant recipients who developed high blood pressure some months after operation. We present here the results of some investigations done in an attempt to elucidate the cause of this recurrence of hypertension and describe also the effect upon the blood pressure of removing the original diseased kidneys.

\section{Definition of hypertension}

For the purpose of this paper, hypertension is defined as persistent elevation of the diastolic blood pressure above $100 \mathrm{mmHg}$.

\section{Patients}

Twenty-four patients were studied. All had had a cadaveric renal graft which functioned for at least 1 month. One patient had had a bilateral nephrectomy prior to transplantation because of uncontrolled hypertension. After transplantation patients received a low sodium diet until a diuresis had occurred but thereafter the sodium intake was not restricted. If hypertension recurred it was treated initially with hypotensive drugs and a low sodium diet. Azathioprine and prednisone were used as immunosuppressive agents. The dose of prednisone was reduced gradually to a minimum of $10 \mathrm{mg} /$ day if there was no evidence of rejection. Other details of management were as previously described (Branch et al., 1970). Bilateral nephrectomy was performed in seven patients 2 months to 1 year after renal transplantation.

\section{Methods}

Extracellular fluid volume was extimated from the volume of dilution ${ }^{82}$ bromide (Nicholson \& Zilva, 1960). Exchangeable sodium was measured with ${ }^{24}$ sodium. Normal ranges in relation to body weight were derived from the data of Moore et al. (1963). Renal function was assessed by frequent measurement of urine output, blood urea, serum creatinine and creatinine clearance. Urea and creatinine were estimated with an AutoAnalyzer (Technicon). 'True' creatinine was also estimated by the method of Owen et al. (1954). Arteriography of the graft was performed via the contralateral femoral artery. Plasma renin levels were measured by the method of Brown et al. (1964); venous samples were taken from the antecubital vein without compression of the arm, separated immediately and stored at $-20^{\circ} \mathrm{C}$.

\section{Results}

The incidence of hypertension after renal transplantation is shown in Fig. 1. At the time of opera- 
tion $52 \%$ of the patients had hypertension. By 1 month after operation the incidence had fallen to only $17 \%$ but it then increased rapidly, so that by 5 months after operation $83 \%$ of the patients were hypertensive. Approximately half of the patients with hypertension at 5 months had a normal blood pressure before renal transplantation. The reduction in the number of patients with hypertension at 6-7 months (Fig. 1) is due to improvement in two patients following removal of the original diseased kidneys.

The relation between hypertension and extracellular fluid volume is shown in Fig. 2. Several patients developed high blood pressure despite a falling or steady extracellular fluid volume.

The relationship between hypertension and exchangeable sodium is shown in Fig. 3. Again, in several instances, the blood pressure increased as the exchangeable sodium fell to within the normal range.

Renal arteriography was performed in ten patients with hypertension. Some narrowing at the origin of the donor renal artery was found in two patients but this was probably not of functional significance because, in one, blood pressure fell to normal after removal of his original diseased kidneys without correction of the graft renal artery stenosis.

The haemoglobin rose to over $17 \mathrm{~g} / 100 \mathrm{ml}$ and the packed cell volume to over $50 \%$ in three patients, but while all three did have hypertension this first appeared at a time when they were anaemic. The other patients with hypertension did not have polycythaemia.

Table 1 shows the relationship between hypertension and the mean daily dose of prednisone. Despite a fall in mean daily dose from $37.5 \mathrm{mg}$ at 1 month to $19 \mathrm{mg}$ at 5 months the incidence of hypertension increased from 17 to $83 \%$. Hypertension persisted even when the dose of prednisone had been between 10 and $15 \mathrm{mg} /$ day for several months.

Figure 4 demonstrates the relationship between hypertension and creatinine clearance. Of the twelve

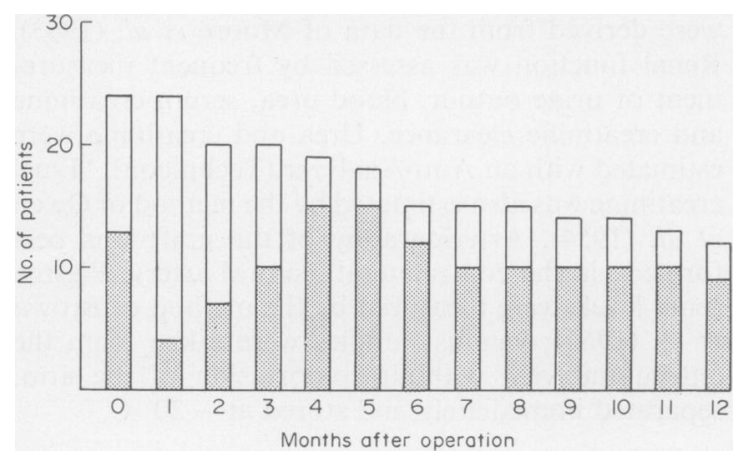

Fig. 1. Incidence of hypertension after cadaveric renal transplantation. Open columns, normotensive patients; stippled columns, hypertensive patients.

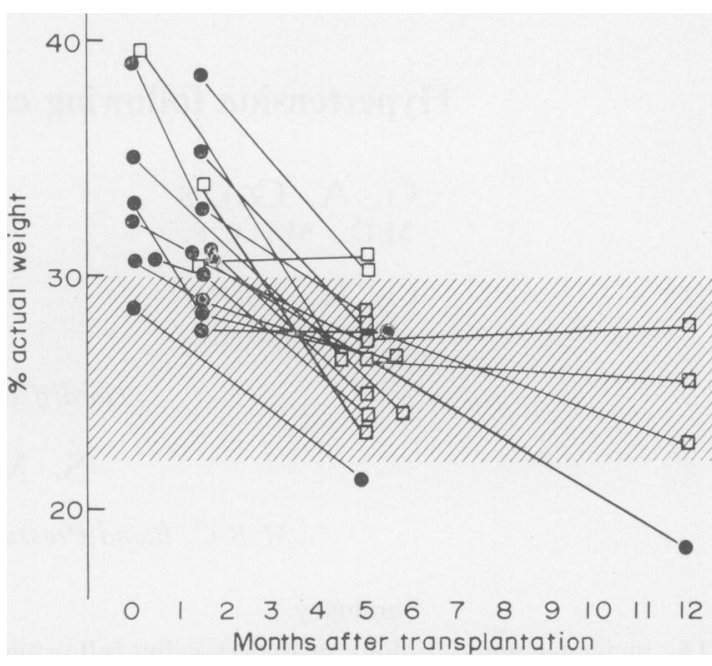

Fig. 2. Relationship between hypertension after cadaveric renal transplantation and changes in extracellular fluid. (Extracellular fluid expressed as \% actual weight.) The normal range is indicated by the shaded area. Normotensive patients; $\square$, hypertensive patients.

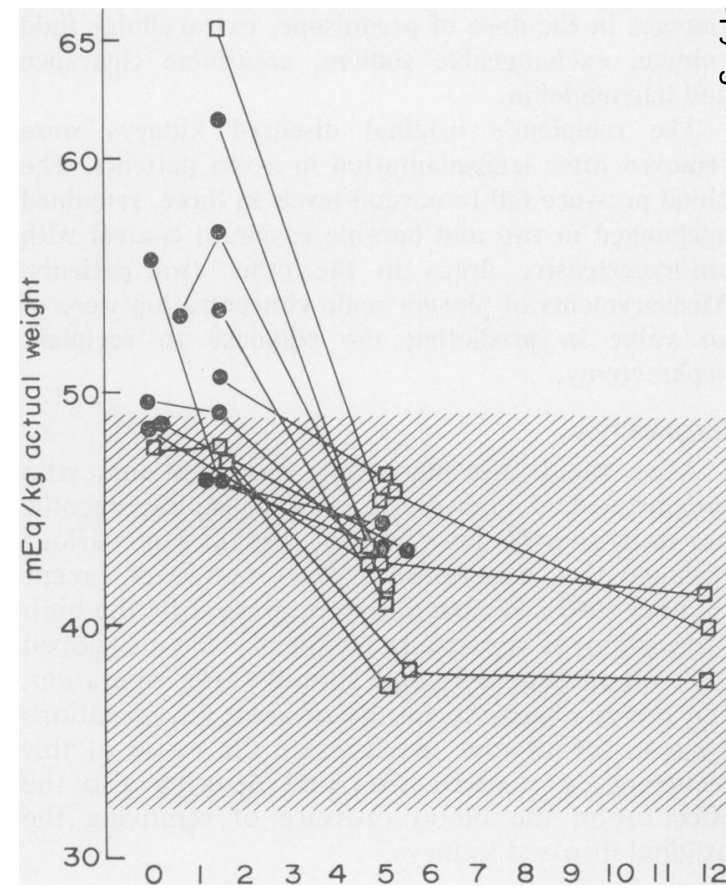

Fig. 3. Relationship between hypertension after cadaveric renal transplantation and changes in exchangeable sodium. (Exchangeable sodium expressed as $\mathrm{mEq} / \mathrm{kg}$ actual weight.) 0 , Normotensive patients; $\square$, hypertensive patients. 
TABLE 1. The relationship of hypertension after cadaveric renal transplantation to the daily dose of prednisone

\begin{tabular}{cccc}
\hline Month & $\begin{array}{c}\text { No. of } \\
\text { patients }\end{array}$ & $\begin{array}{c}\text { Mean daily prednisone } \\
\text { dose (mg) }\end{array}$ & $\begin{array}{c}\% \text { hyper- } \\
\text { tensive }\end{array}$ \\
\hline 0 & 24 & $(100)$ & 50 \\
1 & 24 & $37 \cdot 5$ & 17 \\
2 & 20 & $37 \cdot 5$ & 35 \\
3 & 20 & $23 \cdot 9$ & 50 \\
4 & 19 & $22 \cdot 4$ & 79 \\
5 & 18 & $19 \cdot 0$ & 83 \\
6 & 15 & $15 \cdot 8$ & 80 \\
7 & 14 & $17 \cdot 7$ & 71 \\
8 & 14 & $16 \cdot 4$ & 71 \\
9 & 14 & $16 \cdot 4$ & 71 \\
10 & 14 & $15 \cdot 4$ & 71 \\
11 & 13 & $13 \cdot 5$ & 77 \\
12 & 12 & $13 \cdot 1$ & 75 \\
\hline
\end{tabular}

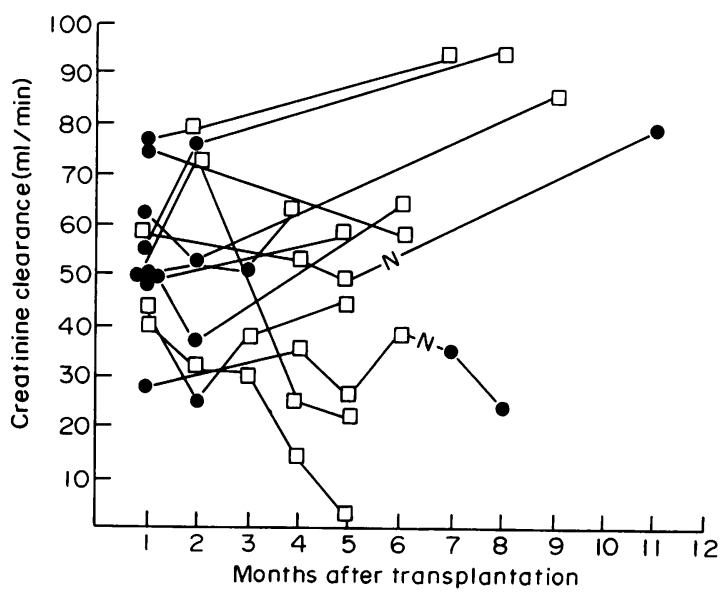

FIG. 4. Relationship between hypertension after cadaveric renal transplantation and changes in creatinine clearance. O, Normotensive patients; $\square$, hypretensive patients; $\mathbf{N}$, bilateral nephrectomy.

patients with hypertension in whom regular clearance measurements were made, nine developed hypertension at a time when creatinine clearance was rising steadily; one subsequently developed chronic rejection of the graft. In only one patient did hypertension and a falling creatinine clearance appear to be associated. In most patients, hypertension appeared when the serum creatinine concentration was either steady or falling.

Hypertension developed during an acute rejection episode on three occasions but did not persist after the rejection was reversed. In eight other unequivocal episodes of acute rejection there was no elevation of blood pressure.

In three patients there was a progressive decline in renal function due to chronic rejection. Two of these had persistent hypertension but the other patient remained normotensive, despite an increase in the dose of prednisone.
Warm ischaemia time varied from 40 to $110 \mathrm{~min}$. There was no relationship between warm ischaemia time and subsequent development of hypertension.

The recipients' original kidneys were removed after renal transplantation in seven patients with hypertension. The blood pressure fell to normal in three and hypotensive drugs were discontinued (Fig. 5). Two patients showed no significant change in blood pressure after operation. In the remaining two the blood pressure did fall after bilateral nephrectomy but some hypotensive drugs were still required in order to keep the diastolic pressure below $100 \mathrm{mmHg}$.

Plasma renin concentration was estimated in five of these seven patients a few days before and 1 month after bilateral nephrectomy. Two separate samples were taken for each analysis. The results are shown in Table 2. None of the patients had markedly raised plasma renin levels but slightly raised values were found in three. There was no correlation between plasma renin concentration and exchangeable sodium. There was no significant change as a result of bilateral nephrectomy and the blood pressure response bore no relation to any change in plasma renin concentration.

TABLE 2. Measurements of plasma renin concentration before and after bilateral nephrectomy in patients who had received a cadaveric renal transplant

\begin{tabular}{|c|c|c|c|c|c|}
\hline \multirow{2}{*}{ Patient } & \multicolumn{4}{|c|}{$\begin{array}{l}\text { Plasma renin } \\
\text { concentration }\end{array}$} & \multirow{2}{*}{$\begin{array}{l}\text { Response of } \\
\text { blood pressure } \\
\text { to operation }\end{array}$} \\
\hline & \multicolumn{2}{|c|}{$\begin{array}{l}\text { Before } \\
\text { (units) }\end{array}$} & \multicolumn{2}{|c|}{$\begin{array}{l}\text { After } \\
\text { (units) }\end{array}$} & \\
\hline K.A. & $16 \cdot 8$ & $26 \cdot 5$ & 13.9 & $23 \cdot 6$ & Good \\
\hline D.B. & $15 \cdot 6$ & $20 \cdot 3$ & $20 \cdot 6$ & $17 \cdot 1$ & Partial \\
\hline C.W. & $13 \cdot 9$ & 14.9 & $10 \cdot 3$ & $17 \cdot 9$ & Partial \\
\hline R.J. & $26 \cdot 4$ & $5 \cdot 9$ & $18 \cdot 9$ & $11 \cdot 3$ & Nil \\
\hline A.J. & $12 \cdot 9$ & $13 \cdot 9$ & 13.9 & $10 \cdot 5$ & Nil \\
\hline
\end{tabular}

Two separate venous samples were estimated at intervals of 2-24 hr a few days before and 1 month after operation. (Normal range 4-20 units. M.R.C. Blood Pressure Research Unit, Glasgow.)

\section{Discussion}

Hume (1967) lists several possible causes of recurrence of hypertension after renal transplantation. These include renal artery stenosis, ischaemia of the transplant, acute rejection, sodium and water retention, prednisone therapy and chronic rejection. None of these adequately explains the high recurrence rate of hypertension in the present series of cadaverdonor transplants. The incidence of post-transplant hypertension was considerably higher than that previously reported after living-donor transplants (Ducrot et al., 1965; Starzl et al., 1964).

Immediately after the postoperative diuresis, blood pressure fell to normal levels in all but a small proportion of cases. The relief of hypertension during 


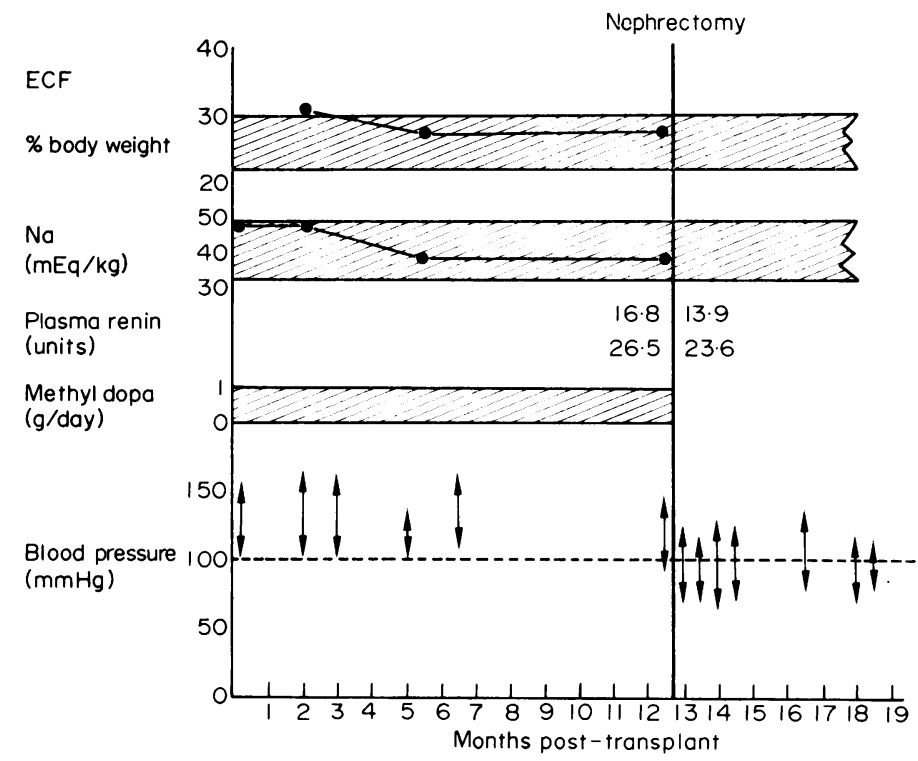

FIG. 5. Changes in blood pressure, hypotensive therapy, plasma renin concentration, exchangeable sodium and extracellular fluid after bilateral nephrectomy in a patient who was hypertensive after a cadaveric renal transplant.

this period is probably related to a reduction in extracellular fluid volume and exchangeable sodium (Ducrot et al., 1965; Swales, 1967; Coles, 1972). A similar relationship has been observed in patients treated by regular haemodialysis (Blumberg et al., 1967; Comty, Rottka \& Shaldon, 1964). Recurrence of hypertension in the majority of our patients at a later stage cannot, however, be attributed to salt and water retention because exchangeable sodium and extracellular fluid volume remained normal.

Starzl et al. (1964) thought that the recurrence of hypertension after transplantation was related to corticosteroid therapy. It is difficult to assess the role of steroids in our patients but hypertension often appeared as the dose of prednisone was being reduced, and persisted even after 6 months on a dose of only $10-15 \mathrm{mg} / \mathrm{day}$. Patients with asthma treated by prednisone may develop hypertension but the incidence is considerably lower than in our patients (Pearson, Baylis \& Smellie, 1961; Rees and Williams, 1962). This may be because the cumulative dose given to transplant recipients is usually higher. Prednisone probably causes hypertension by a mechanism related to its sodium-retaining properties (Thomas, 1968) but total exchangeable sodium was not excessive in the patients described here. Goldman, Meredith \& Reeve (1969) noted that after living-donor transplants the blood pressure fell but that this did not occur after cadaver-donor transplants. A more potent sodium-retaining steroid, deoxycortisone acetate, produces hypertension more readily in nephritic than in control rats (Knowlton et al., 1946) It is not known whether ischaemic damage or milde rejection of a renal transplant also potentiates the hypertensive effect of prednisone but this could explain the observations of Goldman et al. (1969), since damage is more likely after cadaver-donor transplantation. Dexamethasone, which has no sodium-retaining properties (Bunim et al., 1958) has not been widely used for immunosuppression and might be preferable to prednisone in patients with hypertension.

Surgical correction of stenosis at the site of anastomosis of the donor renal artery sometimes cures posttransplant hypertension (Hamburger, Crosnier \& Dormont, 1965). In only two of our hypertensive patients was there any arteriographic evidence of narrowing of the renal artery. The difficulty in assessing the functional significance of the arteriographic appearances is illustrated by the fact that in one patient the hypertension was relieved by bilateral nephrectomy without correction of the apparent renal artery stenosis.

Erythraemia may occur after renal transplantation and may be associated with hypertension (Swales \& Evans, 1969). Three of our patients had erythraemia but they developed hypertension when they were anaemic.

In experimental animals, ischaemia of the transplant apparently causes late-onset hypertension 
(Simso, Telander \& Hitchcock, 1963) but this has not been reported in man. There was no relationship between the duration of warm ischaemia and either early or late onset of hypertension in our patients. Cadaver kidneys must inevitably be subjected to more prolonged ischaemia than living-donor kidneys but wherher this explains the higher incidence of hypertension in the former (Advisory Committee of the Human Kidney Transplant Registry, 1969) is not known.

Hypertension commonly occurs during acute rejection (Starzl et al., 1964). This has been attributed to sodium retention (Swales, 1967) and to elevation of plasma renin levels (Gunnels, Stickel \& Robinson, 1966; West, Turcotte \& Vander, 1969), though hype1tension can occur during rejection without any change in plasma renin concentration (Abbrecht, Vander \& Turcotte, 1969). In the present series, hypertension occurred during some but not all rejection crises; it did not persist after the rejection had been reversed. Similar observations have been made by Blaufox et al. (1966).

The association of hypertension and chronic rejection is well recognized (Hume, 1967) and chronic rejection was probably responsible for the hypertension in two of our patients. Most of the patients, however, developed progressive hypertension while the creatinine clearance was steadily improving. Goldman et al. (1969) found that most transplant recipients with hypertension had a plasma creatinine concentration greater than $1.5 \mathrm{mg} / 100 \mathrm{ml}$, compared with a mean value of $1.3 \mathrm{mg} / 100 \mathrm{ml}$ in normotensive patients. The plasma creatinine was greater than $1.5 \mathrm{mg} / 100 \mathrm{ml}$ in most of our patients but the values remained constant for up to 1 year after operation. Nevertheless, a very slow rejection process must be considered the most likely cause of the hypertension. It is difficult to explain why the hypertension should recur a few months after transplantation, rather than immediately, on any other grounds.

The role of renin in the development of hypertension after renal transplantation is uncertain. West et al . (1969) found a significant but poor correlation between plasma renin levels and blood pressure, but Blaufox et al. (1966) and Verniory et al. (1967) did not. When measured, plasma renin levels were virtually normal in our patients, though it could be argued that in the presence of hypertension they were inappropriately high (Lee, 1969).

\section{The effects of bilateral nephrectomy}

The indications for bilateral nephrectomy in the present series were not clear cut. Hypertension in transplant recipients is usually controlled by antihypertensive drugs (Goldman et al., 1969) and in none of our patients can it be claimed that the blood pressure was uncontrollable by drug therapy. How- ever, all the patients in whom bilateral nephrectomy was done had presented originally with severe hypertension and were very alarmed by its recurrence. They required increasing doses of antihypertensive drugs and some complained of troublesome sideeffects. Bilateral nephrectomy successfully controlled the blood pressure in three of seven patients. In two others the hypertension became easier to manage by drug therapy as previously reported by Goldman et al. (1969) and Papadimitriou, Chisholm \& Shackman (1969). In contrast, plasma renin concentration is usually very high in patients on regular haemodialysis who remain hypertensive despite removal of excess extracellular fluid, and the hypertension is usually relieved by bilateral nephrectomy in these patients (Brown et al., 1969).

Bilateral nephrectomy after transplantation is not without risk. One patient developed a large abscess at the site of operation and another had a temporary pneumothorax. It is our current practice to perform bilateral nephrectomy before, rather than after, renal transplantation in patients with severe hypertension which is difficult to control by regular dialysis and drugs. Pre-transplant nephrectomy is probably less hazardous than post-transplant nephrectomy but it is difficult to decide which patients require it. Despite pre-transplant nephrectomy, even living-donor recipients may sometimes develop hypertension after renal transplantation (Starzl et al., 1964).

\section{Acknowledgment}

We are grateful to Dr A. F. Lever for helpful criticism.

\section{References}

Abbrecht, P.H., Vander, A.J. \& Turcotte, J.G. (1969) Effects of saline loading on the renin, erythropoietin, and blood pressure responses to canine renal allotransplantation. Circulation Research, 25, 99.

Advisory Committee of THE Human Kidney Transplant REGISTRY (1969) Description of kidney transplant function during first year. Transplantation, 8, 728.

Blaufox, M.D., Birbari, A.E., Hickler, R.B. \& Merrill, J.P. (1966) Peripheral plasma renin activity in renal homotransplant recipients. New England Journal of Medicine, 275, 1165 .

Blumberg, A., Nelp, W.B., Hegstrom, R.M. \& Scribner, B.H. (1967) Extracellular volume in patients with chronic renal disease treated for hypertension by sodium restriction. Lancet, ii, 69.

Branch, R.A., Coles, G.A., Crosby, D.L., Jones, J.H., Sussman, M. \& Thomas, W.J.C. (1970) Integrated regional haemodialysis and renal transplantation centre. British Medical Journal, 1, 291.

Brown, J.J., Curtis, J.R., Lever, A.F., Robertson, J.I.S., DE WARDENER, H.E. \& WING, A.J. (1969) Plasma renin concentration and the control of blood pressure in patients on maintenance haemodialysis. Nephron, 6, 329.

Brown, J.J., Davies, D.L., LeVer, A.F., Robertson, J.I.S. \& TREE, M. (1964) The estimation of renin in human plasma. Biochemical Journal, 93, 594. 
Bunim, J.J., Black, R.L., Lutwak, L., Peterson, R.E. \& Whedon, G.D. (1958) Studies on dexamethasone, a new synthetic steroid, in rheumatoid arthritis-a preliminary report. Adrenal cortical, metabolic and early clinical effects. Arthritis and Rheumatism, 1, 313.

Coles, G.A. (1972) Body composition in chronic renal failure. Quarterly Journal of Medicine (in press).

Comty, C.M., RottKa, H. \& Shaldon, S. (1964) Blood pressure control in patients with end-stage renal failure treated by intermittent haemodialysis. Proceedings of the European Dialysis and Transplant Association, 1, 209.

Ducrot, H., Jungers, P., Funck-Brentano, J.-L., Perrin, D., Crosnier, J. \& Hamburger, J. (1965) La correction de l'hypertension arterielle par la transplantation renale chez l'homme. Pathologie et Biologie, 13, 1070.

Goldman, R., Meredith, W.T. \& Reeve, C.E. (1969) Blood pressure levels and hypertension in patients surviving renal homotransplantation at least one year. In: Abstracts IFree Communications IVth International Congress of Nephrology, Stockholm, p. 330.

GunNells, J.C. Jr., Stickel, D.L. \& Robinson, R.R. (1966) Episodic hypertension associated with positive renin assays after renal transplantation. New England Journal of Medicine, 274, 543.

Hamburger, J., Crosnier, J. \& Dormont, J. (1965) Experience with 45 renal homotransplantations in man. Lancet, $\mathbf{i}$, 985.

HumE, D.M. (1967) Renal homotransplantation in man. Annual Review of Medicine, 18, 229.

Knowlton, A.I., Stoerk, H., Seegal, B.C., \& Loeb, E.N. (1946) Influence of adrenal cortical steroids upon the blood pressure and the rate of progression of experimental nephritis in rats. Endocrinology, 38, 315.

LEE, M.R. (1969) Renin and Hypertension, p. 167. Lloyd-Luke, London.

Moore, F. D., Olesen, K.H., McMurrey, J.D., Parker, H.V., BALl, M.R. \& Boyden, C.M. (1963) The Body Cell Mass and Its Supporting Environment. W. B. Saunders, Philadelphia.
Nicholson, J.P. \& Zilva, J.F. (1960) Estimation of extracellular fluid volume using radiobromine. Clinical Science, 19, 391 .

Owen, J.A., Iggo, B., Scandrett, F.J. \& Stewart, C.P. (1954) The determination of creatinine in plasma or serum, and in urine; a critical examination. Biochemical Journal, 58, 426.

Papadimitriou, M., Chisholm, G.D. \& Shackman, R. (1969) Hypertension in patients on regular haemodialysis and after renal allotransplantation. Lancet, i, 902.

Pearson, R.S.B., Baylis, J.H. \& SMellie, H.C. (1961) Treatment of chronic asthma with prednisolone and the newer steroids. British Medical Journal, 1, 315.

Rees, H.A. \& Williams, D.A. (1962) Long-term steroid therapy in chronic intractable asthma. British Medical Journal, 1, 1575.

Simso, L.A., Telander, R.L. \& Hitchcock, C.R. (1963) Hypertension following renal autografting in the Kenya baboon. Surgical Forum, 14, 170.

Starzl, T.E., Marchioro, T.L., Porter, K.A., Moore, C.A, RifKIND, D. \& WADDELL, W.R. (1964) Renal homotransplantation: late function and complications. Annals of Internal Medicine, 61, 470.

Swales, J.D. (1967) Sodium metabolism in relation to changing blood pressure levels in human renal transplantation. American Journal of Medical Science, 253, 531.

Swales, J.D. \& Evans, D.B. (1969) Erythraemia in renal transplantation. British Medical Journal, 2, 80.

Thomas, J.P. (1968) A Guide to Steroid Therapy, p. 50. Lloyd-Luke, London.

Verniory, A., Cuykens, J.J., Lotteau, B. \& Toussaint, C. (1967) Dosage de la renine plasmatique dans l'hypertension renale (renovasculaire ou parenchymateuse). Effets de la reconstruction vasculaire, de la nephrectomie et de la greffe renale. Journal d'Urologie et Nephrologie, 73, 276.

West, T.H., Turcotte, J.G. \& VAnder, A. (1969) Plasmaco renin activity, sodium balance, and hypertension in a group of renal transplant recipients. Journal of Laboratory and Clinical Medicine, 73, 564. 